equipped with a 150 lines $\mathrm{mm}^{-1}$ grating and registered by an optical multichannel analyzer (OMA, Hamamatsu Photonics, PMA50).

Received: July 17, 2003 Final version: September 16, 2003

[1] T. Miteva, A. Meisel, W. Knoll, H. G. Nothofer, U. Scherf, D. C. Mueller, K. Meerholz, A. Yasuda, D. Neher, Adv. Mater. 2001, 13, 565.

[2] a) R. Pacios, D. D. C. Bradley, J. Nelson, C. J. Brabec, Synth. Met. 2003 137, 1469. b) D. M. Russell, A. C. Arias, R. H. Friend, C. Silva, C. Ego, A. C. Grimsdale, K. Mullen, Appl. Phys. Lett. 2002, 80, 2204.

[3] X. Long, A. Malinowski, D. D. C. Bradley, M. Inbasekaran, E. P. Woob, Chem. Phys. Lett. 1997, 272, 6.

[4] R. Xia, G. Heliotis, D. D. C. Bradley, Appl. Phys. Lett. 2003, 82, 3599.

[5] H. Sirringhaus, R. J. Wilson, R. H. Friend, M. Inbasekaran, W. Wu, E. P Woo, M. Grell, D. D. C. Bradley, Appl. Phys. Lett. 2000, 77, 406.

[6] M. Ariu, D. G. Lidzey, M. Sims, A. J. Cadby, P. A. Lane, D. D. C. Bradley, J. Phys.: Condens. Matter 2002, 14, 9975

[7] R. Schroeder, B. Ullrich, W. Graupner, U. Scherf, J. Phys.: Condens. Matter 2001, 13, L313.

[8] E. L. Falcao-Filho, C. B. Araujo, Y. Messaddeq, J. Appl. Phys. 2002, 92, 3065 .

[9] a) P. M. Petroff, N. Horiguchi, US Patent 6541 788, 2003. b) J. Lindmayer, US Patent $4862960,1989$.

[10] a) T. Kojei, D. Beljonne, F. Meyers, J. W. Perry, S. R. Marder, J. L. Bredas, Chem. Phys. Lett. 1998, 298, 1. b) G. S. He, D. Bhawalker, C. F. Zhao, C. K. Park, R. N. Prasad, Appl. Phys. Lett. 1996, 68, 3549. c) R. Schroeder, W. Graupner, U. Scherf, B. Ullrich, J. Chem. Phys. 2002, 116, 3449.

[11] A. Samoc, M. Samoc, B. Luther Davies, Polish J. Chem. 2002, 76, 345.

[12] M. Drobizhev, A. Karotki, M. Kruk, A. Krivokapic, H. L. Anderson, A. Rebane, Chem. Phys. Lett. 2003, 370, 690.

[13] J. L. Clark, G. Rumbles, Phys. Rev. Lett. 1996, 76, 2037.

[14] D. Dolphin, The Porphyrins, Vol. 3, Academic Press, New York 1978

[15] Note that data represented by Fig. 4 are relevant for a practitioner who needs to select appropriate dopant for the given laser wavelength, e.g., custom available and low-cost second harmonic of the Nd:YAG laser.

[16] M. Pope, C. Swenberg, Electronic Processes in Organic Crystals, Clarendon Press, Oxford 1982

[17] H. G. Nothofer, A. Meisel, T. Miteva, D. Neher, M. Forster, M. Oda G. Lieser, D. Sainova, A. Yasuda, D. Lupo, W. Knoll, U. Scherf, Macromol. Symp. 2000, 154, 139.

\section{Synthesis and Characterization of Magnetic Iron Sulfide Nanowires}

\section{By Manashi Nath, Amitava Choudhury, Asish Kundu, and C. N. R. Rao*}

A variety of inorganic nanowires have been synthesized in the last three to four years. ${ }^{[1]}$ Among these, magnetic nanowires are of interest because of their potential applications in magnetic recording and other areas. Nanowires and nanorods of magnetic metals, such as $\mathrm{Fe}, \mathrm{Co}$, and $\mathrm{Ni}^{\left[{ }^{[2]}\right.}$ and their alloys ${ }^{[3]}$ have been prepared by employing template-directed synthesis. Although there are reports of nanotubes, nanorods, and nanowires of several metal chalcogenides, ${ }^{[4,5]}$ oxides, ${ }^{[6]}$ and nitrides $^{[1,6]}$ there is no report to date on iron sulfide nanowires,

[*] Prof. C. N. R. Rao, M. Nath, Dr. A. Choudhury, A. Kundu Chemistry and Physics of Materials Unit

Jawaharlal Nehru Center for Advanced Scientific Research Jakkur P.O., Bangalore 560064 (India)

E-mail: cnrrao@jncasr.ac.in

Prof. C. N. R. Rao, M. Nath, Dr. A. Choudhury

Solid State and Structural Chemistry Unit

Indian Institute of Science

Bangalore 560012 (India) possibly because of the inherent difficulty in the synthesis and control of stoichiometry of these materials. The Fe-S system has a complex phase diagram, with broad range of compositions of $\mathrm{Fe}_{1-x} \mathrm{~S}$ (pyrrhotite) phases ${ }^{[7]}$ occurring between FeS and $\mathrm{FeS}_{2}$, showing interesting magnetic ${ }^{[8-10]}$ and electrical properties. ${ }^{[11]} \mathrm{Fe}_{7} \mathrm{~S}_{8}$ is a well-defined phase in this region, showing ferrimagnetism with $T_{\mathrm{N}}=600 \mathrm{~K} .{ }^{[9]}$ We deemed it important to synthesize iron sulfide nanowires by virtue of their interesting chemistry and magnetic properties. In this communication, we report the first successful synthesis of semiconducting nanowires of $\mathrm{Fe}_{1-x} \mathrm{~S}(x \approx 0.12,0.09)$, of which the $\mathrm{Fe}_{0.88} \mathrm{~S}\left(\mathrm{Fe}_{7} \mathrm{~S}_{8}\right)$ nanowires are ferrimagnetic, showing magnetic hysteresis at room temperature.

In order to synthesize $\mathrm{Fe}_{1-x} \mathrm{~S}$ nanowires, a hybrid composite (I) with ethylenediamine was first prepared by solvothermal procedure (see Experimental). Scanning electron microscopy (SEM) and transmission electron microscopy (TEM) images of the composite I showed the presence of a high yield of lengthy nanowires with diameters in the range of 80-150 nm and lengths of several micrometers as shown in Figure 1. The infrared (IR) spectrum showed characteristic peaks of the amine, although the bands due to $\mathrm{C}-\mathrm{N}$ and $\mathrm{N}-\mathrm{H}$ stretching frequencies were considerably shifted towards lower values due to the bound nature of the amine. Energy dispersive X-ray (EDX) analysis of several samples of $\mathbf{I}$ carried out over different regions of each sample gave an average Fe/S ratio of
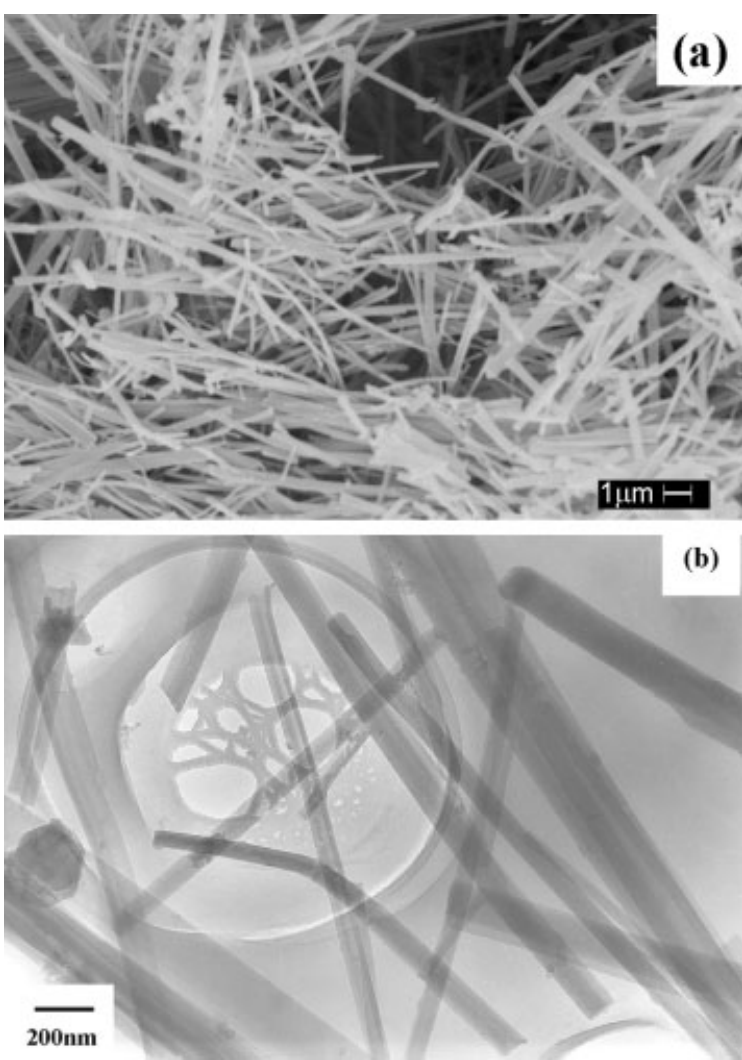

Fig. 1. a) SEM image of the organic-inorganic composite, $\mathrm{Fe}_{1-x} \mathrm{~S}(\mathrm{en})_{0.5}$, I b) Low-magnification TEM image of composite I. Apart from nanowires, some layer-rolled kind of structures are also observed (as seen in the center of the image). 


\section{ADVANCED \\ MATERIALS}

0.7-0.8:1. The C, H, N analysis of $\mathbf{I}$ gave the percentages to be $11.2462,3.8355$, and $11.9318 \%$, respectively, corresponding to the nominal formula, $\mathrm{Fe}_{1-x} \mathrm{~S}(\mathrm{en})_{0.5} \quad(x=0.2-0.3$, en =ethylenediamine). $\quad$ Thermogravimetric analysis of I showed a sharp weight loss around $200{ }^{\circ} \mathrm{C}$ due to the loss of the amine bound to the metal center. ${ }^{[12]}$ The powder X-ray diffraction (XRD) pattern of $\mathbf{I}$ showed the presence of a low-angle line at $\sim 8 \AA$, in addition to broad, weak reflections. The low-angle line is similar to that found in many of the organic-inorganic composites of $\mathrm{CdE}$ and $\mathrm{ZnE}(\mathrm{E}=\mathrm{S}$, Se) containing metal-chalcogen layers pillared by an amine. ${ }^{[12,13]}$ The nanowires of $\mathrm{Fe}_{1-x} \mathrm{~S}(\mathrm{en})_{0.5}$ were paramagnetic, showing insulating behavior at room temperature.

The amine in I could be removed partially under vacuum. It could, however, be removed completely by heating I to $200-300^{\circ} \mathrm{C}$ under Ar flow (200 sccm, standard cubic centimeters per minute), yielding pure inorganic $\mathrm{Fe}_{1-x} \mathrm{~S}$ nanowires (see Experimental). IR spectra of I heated to $200{ }^{\circ} \mathrm{C}$ and $300^{\circ} \mathrm{C}$ (designated as II, III, respectively) showed the absence of the peaks corresponding to the amine. The XRD patterns of II and III were characteristic of pyrrhotite phases (prominent lines at $d=2.98$, 2.63, 2.05, $1.72 \AA) .{ }^{[14]}$

The SEM image of II in Figure 2a shows an abundant presence of nanowires with lengths of the order of micrometers. EDX analysis of individual nanowires revealed a $\mathrm{Fe} / \mathrm{S}$ ratio of $0.88: 1$, indicating the composition to be $\mathrm{Fe}_{7} \mathrm{~S}_{8}$. Low-magnification TEM images of II (Fig. 2b) show the diameters to be in the range 40$180 \mathrm{~nm}$. High-resolution TEM (HRTEM) images show the presence of different domains with interesting lattice fringes (Fig. 2c), but they all belong to the same crystallographic phase. The inset in A shows the simulated fast Fourier-transform (FFT) pattern obtained from the boxed region of the HRTEM image corresponding to a hexagonal close-packed (hcp) lattice with a hexagonal arrangement of the spots that can be indexed to the (204) plane of the $4 \mathrm{C}$ phase of $\mathrm{Fe}_{7} \mathrm{~S}_{8}, \quad(a=12.811, \quad b=6.870$, and $c=11.885 \AA$, $\beta=117.17^{\circ}$, JCPDS file, card number: $29-0723$ ). The layer spacing obtained from the lattice fringes from a different part of the image is $\sim 2.6 \AA$, corresponding to $d(004)$ of $4 \mathrm{C}-\mathrm{Fe}_{7} \mathrm{~S}_{8}$. The electron diffraction (ED) pattern in the inset in B shows spacings of 3.2, 2.6, and $1.7 \AA$ due to the (202), (004), and (040) planes, respectively. The $d(004)$ spots in the ED pattern show splitting due to superstructures of $\mathrm{Fe}_{7} \mathrm{~S}_{8} .4 \mathrm{C}-\mathrm{Fe}_{7} \mathrm{~S}_{8}$ is known to be a stable, ordered phase at room temperature. ${ }^{[7 a]}$

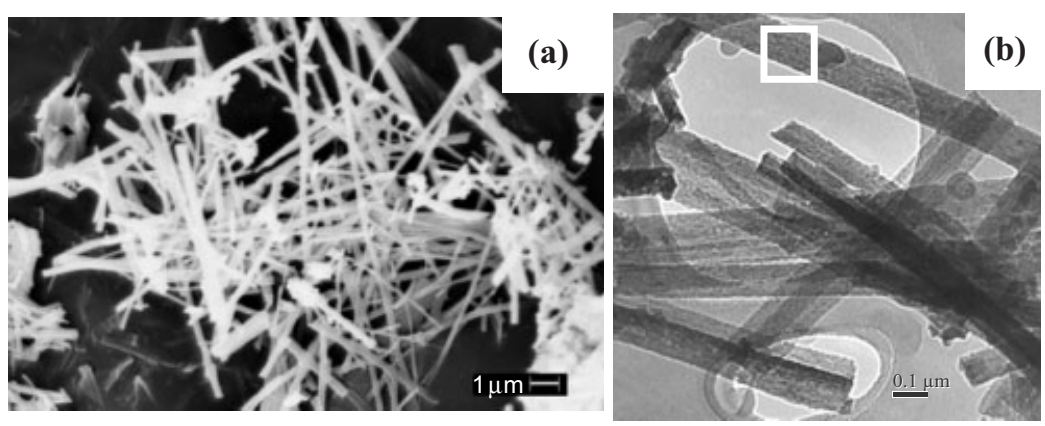

(b)

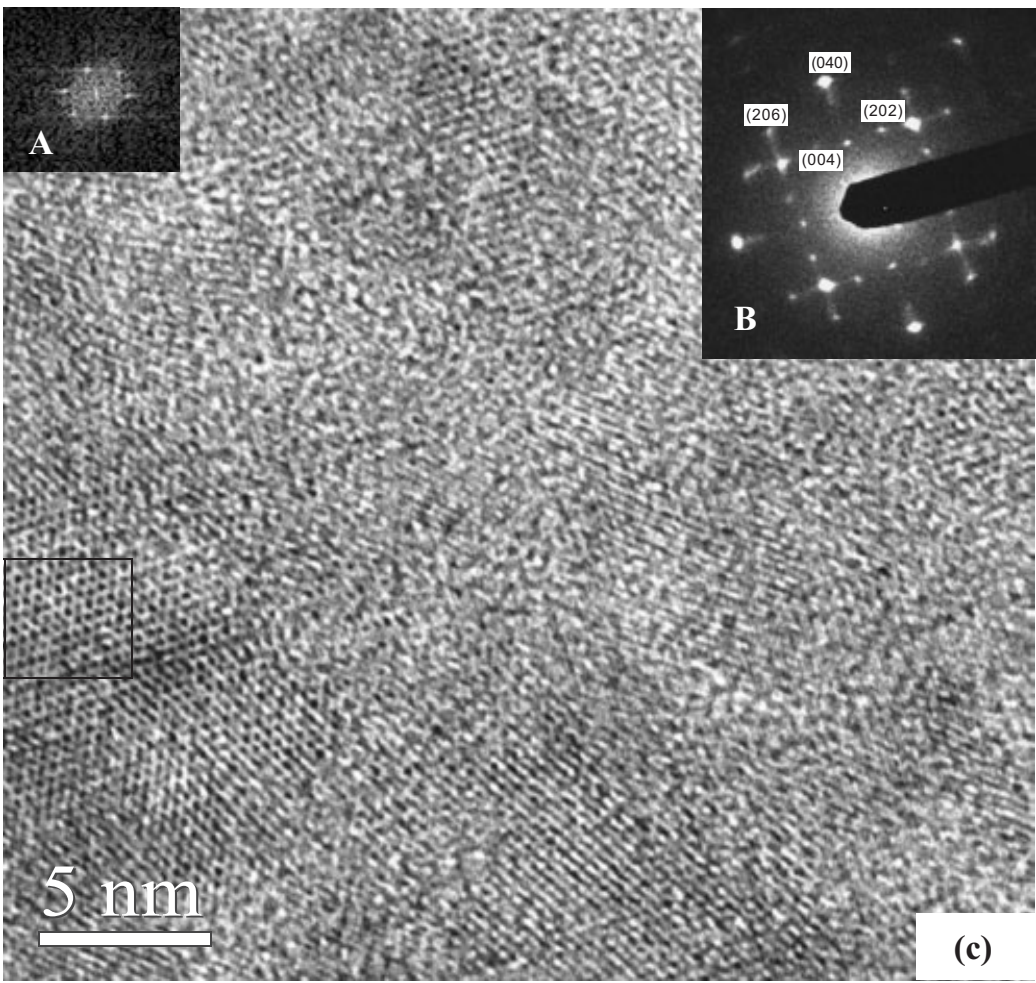

Fig. 2. a) SEM image of the $200^{\circ} \mathrm{C}$ heat-treated product, II, showing a considerable yield of the nanowires. b) Low-magnification TEM image of the nanowires. Some nanowires are obtained in bundles. c) High-resolution image (HRTEM) of the nanowire from the boxed portion of the between the vertices of the hexagon was estimated to be $3.2 \AA$. The simulated FFT pattern from the boxed region in the image is shown in the inset in A, clearly showing the hexagonal arrangement of the spots. The inset in B shows the ED pattern obtained from this nanowire.

The SEM image of III in Figure 3a reveals the presence of a large proportion of nanowires. EDX analysis on these nanowires showed the composition to be $\mathrm{Fe}_{1-x} \mathrm{~S}$ with $x=0.08-0.1$, showing that the amine composite heated at a higher temperature $\left(300^{\circ} \mathrm{C}\right)$ to be less $\mathrm{Fe}$ deficient. Low-magnification TEM images show the presence of short nanowires of 80 $100 \mathrm{~nm}$ diameter in addition to rolled structures as can be seen from Figure $3 \mathrm{~b}$. The rolled structures are not nanotubes or scrolls, but are incompletely folded structures. The HRTEM image of the nanowires shows the lattice fringes marked by the presence of alternate dark and light strips, indicating the presence of a two-layer periodicity. The distance between two dark strips is $\sim 5.6 \AA$, while that between the 

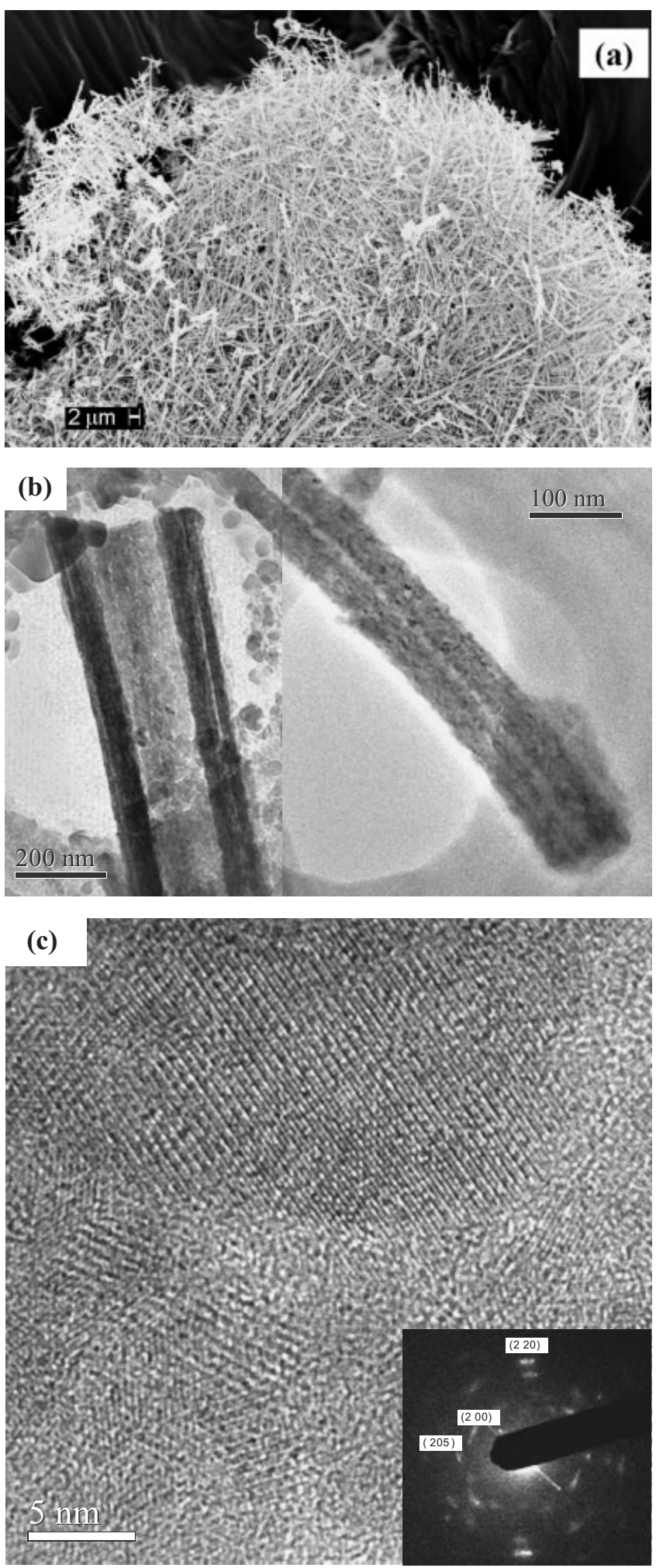

Fig. 3. a) SEM image of the $300^{\circ} \mathrm{C}$ heat-treated product, III, showing a good yield of the nanowires. b) TEM image of III showing some incompletely rolled structures along with nanowires. c) HRTEM image of the nanowires showing periodic stacking of the layers in some region. The inset shows the ED pattern obtained from the nanowires. light strips is $\sim 2.9 \AA$, which correspond to the (102) and (200) planes of 5T-Fe ${ }_{1-x} \mathrm{~S}$ phase [JCPDS file, card number: 29-0724]. The ED pattern from the nanowires shows spots due to (200), (205), and (220) reflections of the 5T-pyrrhotite phase ( $a=6.888$ and $c=28.670 \AA$ ).

Most pyrrhotites exhibit some superstructures as a result of the Fe vacancy ordering, giving rise to varied magnetic and electrical properties and complex phase relations. ${ }^{[7-11]}$ The ordered structure of $\mathrm{Fe}_{7} \mathrm{~S}_{8}$ that can be achieved by the maximum separation of iron vacancy sites is formed by the alternation of partially filled Kagome net layers with fully filled iron layers, i.e., there is an Fe vacancy in every alternate layer. The structure of $\mathrm{Fe}_{1-x} \mathrm{~S}(x \approx 0.1)$ is based on the $\mathrm{Fe}_{7} \mathrm{~S}_{8}$ structure, where partially filled kagome net layers and iron filled layers are stacked in such a way that long-range order is established along the $c$-direction.

The temperature variation of the magnetic susceptibility of II (Fig. 4a) shows a ferrimagnetic behavior with a transition temperature of $\sim 600 \mathrm{~K}$, characteristic of $\mathrm{Fe}_{7} \mathrm{~S}_{8} \cdot{ }^{[9]}$ The Weiss-type behavior can be reversed upon cooling with a thermal hysteresis of 20-25 K. More importantly, nanowires, II, show a hysteresis loop at room temperature (297 K) (see
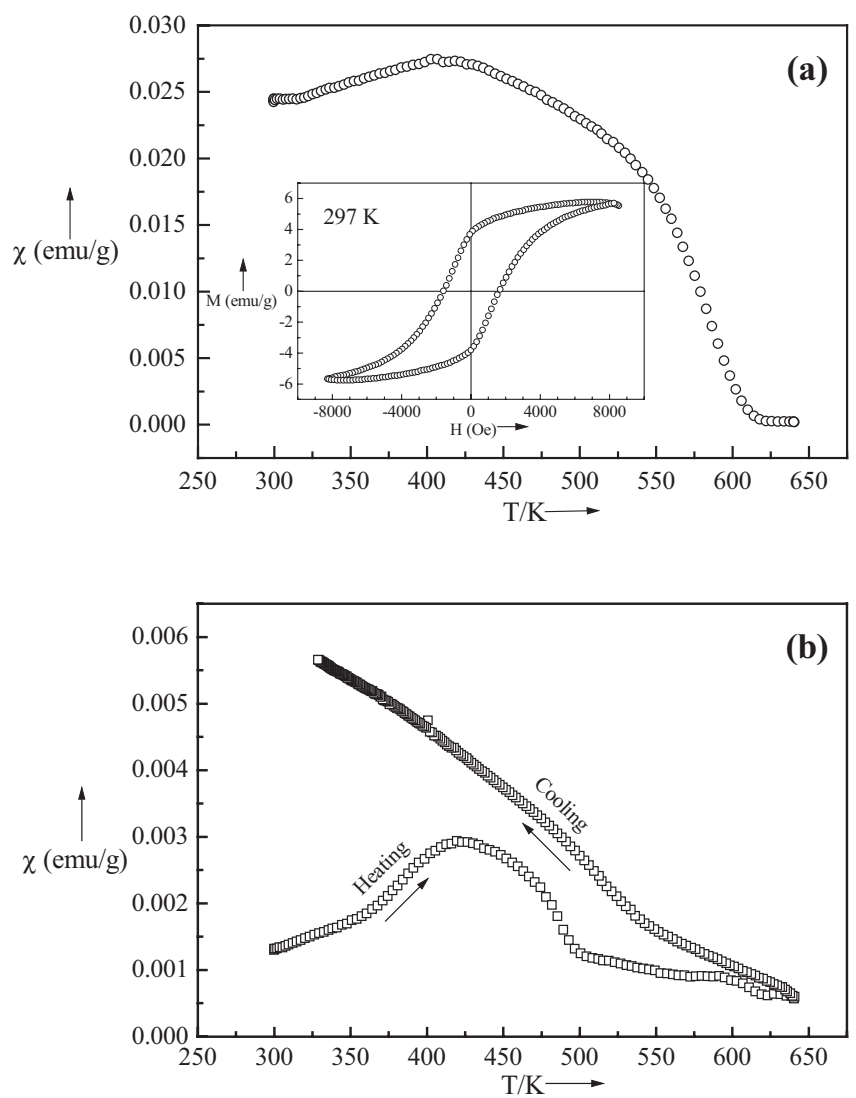

Fig. 4. a) The temperature variation of the magnetic susceptibility between $300-650$ K of II. The inset shows the hysteresis loop obtained at 297 K. b) The temperature variation of the susceptibility between $300-650 \mathrm{~K}$ of III showing peak-type transition in the heating cycle. 
inset of Fig. 4a). A saturation magnetization of $6 \mathrm{emu} \mathrm{g}^{-1}$ $\left(1 \mathrm{emu} \mathrm{g}^{-1}=1 \mathrm{~A} \mathrm{~m}^{2} \mathrm{~kg}^{-1}\right)$ is achieved with an applied field of $8000 \mathrm{Oe}\left(1 \mathrm{Oe}=10^{-4} \mathrm{~T}\right)$. The remnant magnetization and coercivity are $4 \mathrm{emu} \mathrm{g}^{-1}$ and $2000 \mathrm{Oe}$, respectively. The magnetic susceptibility of the $\mathrm{Fe}_{1-x} \mathrm{~S}(x=0.08-0.1)$ nanowires, III, on the other hand, is different from that of II. Nanowires of III show a lambda-type transition ${ }^{[10]}$ at $420 \mathrm{~K}$ in the high-temperature susceptibility data (Fig. 4b). Except in the narrow temperature range of $375-475 \mathrm{~K}$, the ferrimagnetism disappears on either side and predominant antiferromagnetism becomes evident. The antiferromagnetic to paramagnetic transition occurs at $600 \mathrm{~K}$. On cooling the sample, the peak disappears showing a Weiss-type behavior, a mixed behavior common in the $\mathrm{Fe}_{1-x} \mathrm{~S}$ phases. ${ }^{[9]}$ III does not exhibit a hysteresis loop at room temperature and the magnetization is at least one order of magnitude smaller than that of II, indicating predominant antiferromagnetic interactions. We must point out that the magnetic properties reported here represent the average behavior of a bundle of nanowires. It has not been possible to strictly compare the observed properties with those of the bulk, since the literature reports on the bulk properties vary rather widely. Electrical resistivity measurements on pressed pellets of $\mathrm{Fe}_{7} \mathrm{~S}_{8}$ and $\mathrm{Fe}_{1-x} \mathrm{~S}$ nanowires show semiconducting behavior at room temperature and below.

In conclusion, we have been successful in developing a onestep synthesis to produce iron sulfide nanowires of well-defined compositions in high yields. The isolation and characterization of magnetic $\mathrm{Fe}_{7} \mathrm{~S}_{8}$ nanowires are noteworthy.

\section{Experimental}

The synthesis procedure of $\mathrm{Fe}_{1-x} \mathrm{~S}$ nanowires comprises two steps. In the first step, solvothermal methods have been employed to obtain an organic-inorganic composite (I), $\mathrm{Fe}_{1-x} \mathrm{~S}(\mathrm{en})_{0.5}$. The amine removal from this composite by heating under a flow of $\mathrm{Ar}$ at $200-300^{\circ} \mathrm{C}$ yielded nanowires of $\mathrm{Fe}_{1-x} \mathrm{~S}$

Preparation of the Organic-Inorganic Composite, I: In a typical synthesis procedure, $\mathrm{FeCl}_{2} \cdot 4 \mathrm{H}_{2} \mathrm{O}(0.2982 \mathrm{~g}, 1.5 \mathrm{mmol})$ was mixed with $\mathrm{CH}_{3} \mathrm{CSNH}_{2}$ (thioacetamide, $0.2254 \mathrm{~g}, 3 \mathrm{mmol})$ in a Teflon-lined steel autoclave $(23 \mathrm{ml}$ capacity) and $10 \mathrm{~mL}$ ethylenediamine was added to it. The container was sealed and heated to $180^{\circ} \mathrm{C}$ for 4 days under solvothermal conditions. A purple-blackish wool-like flocculate was obtained, which was immediately sonicated in methanol, filtered, washed with methanol, and dried in vacuum. It should be noted that the as-synthesized product is always stored under vacuum as longer exposure to air under ambient conditions leads to conversion of the iron-sulfide phases to the oxide/hydroxide phases. For this reason, after opening the autoclave, sonication and filtration were carried out in minimum time.

Synthesis of $\mathrm{Fe}_{7} \mathrm{~S}_{8}(\boldsymbol{I I})$ and $\mathrm{Fe}_{1-x} \mathrm{~S}$ (III) Nanowires by Amine Removal from the Composite I: The composite I was taken in a quartz boat and placed inside a quartz tube, which was put in a horizontal tubular furnace. The sample was heated under a flow of $\operatorname{Ar}(200 \mathrm{sccm})$ to $200-300{ }^{\circ} \mathrm{C}$ and kept at that temperature for $20-30 \mathrm{~min}$. The furnace temperature was allowed to come down to room temperature naturally before taking out the product. The color of the reactant powder changed to black after the thermal treatment. $\mathrm{Fe}_{7} \mathrm{~S}_{8}$ nanowires (II) were obtained at $200{ }^{\circ} \mathrm{C}$, while at $300^{\circ} \mathrm{C}, \mathrm{Fe}_{1-x} \mathrm{~S}(x=0.08-0.1)$ nanowires (III) were produced.

Characterization: The samples were characterized by powder XRD (Seifert 3000TT), SEM (Leica S440i fitted with Leo software for EDX analysis), TEM (JEOL JEM 3010, operating at $300 \mathrm{kV}$ ), IR spectroscopy (Bruker IFS-66v/S) Magnetic measurements were carried out using a VSM (LakeShore) and by the Faraday technique (Lewis Coil force magnetometer, George Associates).
[1] a) J. Hu, T. Wang Odom, C. M. Leiber, Acc. Chem. Res. 1999, 32, 435. b) Y. Xia, P. Yang, Y. Sun, Y. Wu, B. Mayers, B. Gates, Y. Yin. F. Kim, H.Yan, Adv. Mater. 2003, 15, 353.

[2] a) T. Thurn-Albrecht, J. Schotter, G. A. Kästle, N. Emley, T. Shibauchi, L. Krusin-Elbaum, K. Guarini, C. T. Black, M. T. Touminen, T. P. Russell, Science 2000, 290, 2126. b) J. Bao, C. Tie, Z. Xu, Q. Zhou, D. Shen, Q. Ma, Adv. Mater. 2001, 13, 1631. c) S. Liu, J. Zhu, Y. Matsai, I. Felner, A. Gedanken, Chem. Mater. 2000, 12, 2205. d) L. Sun, P. C. Searson, C. L. Chien, Appl. Phys. Lett. 2001, 79, 4429.

[3] a) J. P. Pierce, E. W. Plummer, J. Shen, Appl. Phys. Lett. 2002, 81, 1890 b) Z. Zhang, D. A. Blom, Z. Gai, J. R. Thompson, J. Shen, S. Dai, J. Am. Chem. Soc. 2003, 125, 7528. c) Y.-G. Guo, L.-J. Wan, C.-F. Zhu, D.-L. Yang, D.-M. Chen, C.-L. Bai, Chem. Mater. 2003, 15, 664.

[4] a) R. Tenne, L. Margulis, M. Genut, G. Hodes, Nature 1992, 360, 444 b) L. Margulis, G. Salitra, R. Tenne, Nature 1993, 365, 113. c) R. Tenne, Chem. Eur. J. 2002, 8, 5303.

[5] a) M. Nath, C. N. R. Rao, J. Am. Chem. Soc. 2001, 123, 4841. b) M. Nath C. N. R. Rao, Angew. Chem. Int. Ed. 2002, 41, 3451. c) C. N. R. Rao, M. Nath, J. Chem. Soc. Dalton Trans. 2003, 1.

[6] P. Yang, Y. Wu, R. Fan, J. Nanosci. Nanotechnol. 2002, 1, 1.

[7] a) H. Nakazawa, N. Morimoto, Mater. Res. Bull. 1971, 6, 345. b) C. N. R. Rao, K. P. R. Pisharody, Prog. Solid State Chem. 1976, 10, 207. c) J. C. Ward, Rev. Pure Appl. Chem. 1970, 20, 175.

[8] a) J. L. Horwood, M. G. Townsend, A. H. Webster, J. Solid State Chem. 1976, 17, 35. b) V. H. Haraldsen, Z. Anorg. Allg. Chem. 1937, 231, 78. c) E. Hirahara, M. Murakami, Phys. Chem. Solids 1958, 7, 281.

[9] F. Li, H. F. Franzen, J. Solid State Chem. 1996, 126, 108.

[10] T. Hirone, S. Maeda, N. Tsuya, J. Phys. Soc. Jpn. 1954, 9, 736.

[11] a) J. M. D. Coey, H. Roux-Buisson, R. Brusetti, J. Phys. (Paris) 1976, 37, C4-1. b) M. G. Townsend, J. R. Gosselin, R. J. Tremblay, A. H. Webster, J. Phys. (Paris) 1976, 37, C4-11. c) J. R. Gosselin, M. G. Townsend, R. J. Tremblay, Solid State Commun. 1976, 19, 799

[12] X. Ouyang, T.-Y. Tsai, D.-H. Chen, Q.-J. Huang, W.-H. Cheng, A. Clearfield, Chem. Commun. 2003, 2886.

[13] a) X. Huang, J. Li, J. Am. Chem. Soc. 2000, 122, 8789. b) Z.-X. Deng, L. Li, Y. Li, Inorg. Chem. 2003, 42, 2331

[14] JCPDS (Joint Committee on Powder Diffraction Standards) files-International Center for Diffraction Data 1997.

\section{Molecular-Scale Interface Engineering of $\mathrm{TiO}_{2}$ Nanocrystals: Improving the Efficiency and Stability of Dye-Sensitized Solar Cells**}

\section{By Peng Wang, Shaik M. Zakeeruddin,* Robin Humphry-Baker, Jacques E. Moser, and Michael Grätzel**}

During the last decade, dye-sensitized solar cells (DSCs) have attracted considerable interest as low-cost alternatives to conventional inorganic photovoltaic devices. ${ }^{[1-3]}$ Although an impressive $10 \%$ solar-to-electricity conversion efficiency could be attained with a panchromatic dye, the achievement of long-term stability at temperatures of $\sim 80-85^{\circ} \mathrm{C}$ has remained a major challenge for a long time. Very recently, an amphiphilic heteroleptic ruthenium sensitizer referred to as Z-907 (cis-Ru( $\left.\mathrm{H}_{2} \mathrm{dcbpy}\right)(\mathrm{dnbpy})(\mathrm{NCS})_{2}$, where the ligand

*] Dr. S. M. Zakeeruddin, Prof. M. Grätzel, Dr. P. Wang, Dr. R. Humphry-Baker, Dr. J. E. Moser Laboratory for Photonics and Interfaces Swiss Federal Institute of Technology Lausanne Lausanne CH-1015 (Switzerland) E-mail: shaik.zakeer@epfl.ch,michael.graetzel@epfl.ch

[**] The present work is supported by the Swiss Science Foundation, Swiss Federal Office for Energy (OFEN), and the European Office of U.S. Air Force under Contract No. F61775-00-C0003. 